\title{
Un caso de afasia con fluencia motriz y paraverbal
}

\section{A case of aphasia with motor and paraverbal fluency}

\author{
David Maldavsky ${ }^{1}$, Jorge Cantis, Rita de Durán y Horacio García Grigera \\ Universidad de Ciencias Empresariales y Sociales, UCES, Argentina
}

(Recepción: Octubre 2007 - Aceptación: Febrero 2008)

\section{Resumen}

Los autores intentan estudiar sistemáticamente las fijaciones pulsionales y las defensas (y su estado) en un caso de afasia que, en el nivel verbal, presenta grandes limitaciones expresivas, las cuales resultan compensadas por la riqueza de recursos paraverbales y gesticulares. Para realizar su análisis los autores aplican el algoritmo David Liberman, un método diseñado precisamente para detectar fijaciones pulsionales y defensas (así como su estado) en el discurso del paciente, y eventualmente en el del terapeuta. Como resultado de su análisis, los autores concluyen que: 1) es conveniente revisar el enfoque freudiano del aparato del lenguaje (que enlaza la representación palabra con la representación-cosa) e incluir al menos otros dos tipos de representación-palabra: las que se enlazan con la representación-cuerpo y las que se enlazan con el pensar inconsciente, 2) cabe preguntarse si la contraposición entre afasia fluente y no fluente constituye un camino pertinente para avanzar hacia el estudio de las diferencias en cuanto a las estructuras clínicas, 3) la oposición entre afasia con la estructura de una neurosis tóxica y la afasia con una organización afín a las neurosis traumáticas ofrece un enfoque útil para pensar las similitudes y diferencias clínicas entre las manifestaciones, 4) ambas organizaciones (tóxicas y traumáticas) a su vez se unifican en torno de una misma defensa (desestimación del afecto) que resulta exitosa en las afasias con una neurosis tóxica y exitoso/fracasada en las afasias con una neurosis traumática, 5) ambas organizaciones psíquicas ponen en evidencia una regresión al funcionamiento del yo-realidad inicial, el más elemental de todos, el cual, además, se halla perturbado.
\end{abstract}

Palabras claves: afasia, defensa, fijación libidinal, neurosis tóxica, neurosis traumática.

\begin{abstract}
The authors intend to systematically study the libidinal fixations and the defenses (as well as their states) in a case of aphasia that, in the verbal level, presents important expressive limitations, which are compensated by the richness of the paraverbal and gesture resources. In their analysis the authors apply the David Liberman algorithm, a method that allows to detect libidinal fixations and defenses (as well as their states) in the patient's and therapist's discourses. The authors conclude: 1) it is convenient to revise the Freudian focus of the language apparatus (that combines the word representation with the thing representation) and to include at least two other types of word-representation: those linked with the body-representation and those connected with the unconscious thinking, 2) the contraposition between fluent and not-fluent aphasias don't seem to be a pertinent way to advance in the studies of the differences about the clinic structures, 3) the opposition between an aphasia with a toxic neurosis structure and an aphasia with an organization related to traumatic neurosis offers a useful focus to think about the clinic similarities and the differences between the manifestations, 4) both organizations (toxic and traumatic) are unified around the same defense (foreclosure of the affect) that results successful in the aphasias with a toxic neurosis and successful/ failed in the aphasias with a traumatic neurosis, 5) both psychic organizations show a regression to a disturbed state of the initial-reality ego, the most elemental psychic structure.
\end{abstract}

Key words: aphasia, defense, libidinal fixation, toxic neurosis, traumatic neurosis 
Deslinde de una perspectiva: comentarios introductorios sobre un libro de Kaplan-Solms y Solms

Existen escasos estudios psicoanalíticos dedicados a la afasia, ninguno de los cuales recurre a un método sistemático de investigación. Por su envergadura, preferimos concentrarnos en un libro reciente de K. Kaplan-Solms y M. Solms, con el objetivo de poner en evidencia nuestra propuesta. El libro Estudios clínicos en neuropsicoanálisis, de K. Kaplan-Solms y M. Solms (2000), consta de tres partes: 1) fundamentos, 2) observaciones, 3) integración. La primera parte propone básicamente una articulación entre las hipótesis de Freud y los desarrollos neuropsicológicos de Luria. La tercera parte propone nuevas articulaciones entre la metapsicología freudiana y los hallazgos de Luria y otros autores en el campo neurobiológico. Con todo, la parte más extensa es la segunda, compuesta por 12 estudios clínicos. En esta segunda parte se realizan observaciones de pacientes con patología cerebral en terapia psicoanalítica. Las perturbaciones cerebrales son diferentes: en la convexidad perisilviana izquierda, en la convexidad perisilviana derecha, en la región frontal ventromedial. Cada una de estas observaciones clínicas posee la misma organización: 1) presentación del caso desde la perspectiva de la lesión, 2) descripción del tratamiento, 3) correlación entre la lesión específica y el funcionamiento psíquico desde la perspectiva psicoanalítica. En una síntesis de los escritos que realizan de la organización psíquica prevalente en cada caso, los autores señalan que en las lesiones del primer grupo predominan perturbaciones ligadas a las palabras (como medio de comunicación y como instrumento para las funciones cognoscitivas), en las perturbaciones del segundo grupo se ha perdido la capacidad para representar objetivos en forma real, y en su reemplazo aparecen modos narcisistas de representación y relación con los objetos, como ocurre en las neurosis narcisistas, a las cuales los autores describen como melancolías o paranoias, mientras que en las perturbaciones del tercer grupo incluso los objetos internos narcisistas están desestructurados, como ocurre en las psicosis.

Esta segunda parte (observaciones clínicas) se propone como un sostén de las argumentaciones de la tercera parte, más abstracta y conceptual. Las argumentaciones expuestas en esta tercera parte poseen un alto grado de refinamiento y muestran el permanente interés de los autores por rescatar la validez de los conceptos freudianos para la comprensión teórica y clínica. Como ejemplo, vale la pena destacar que los autores terminan el libro con una referencia a la teoría de las pulsiones. Por un lado, se refieren a las zonas erógenas y su relación con las vísceras y con los orificios mucosos de la boca, el ano y los genitales, tal como lo planteó Freud (1905d). Por otro lado, se refieren también a las pulsiones de autoconservación y su conexión con los diversos sistemas de comando emocional básico descriptos por Panksepp (1998), junto con las actividades de control propias de la región ventromedial. En cuanto a la pulsión de muerte, la conectan con la tendencia fisiológica más primitiva del tejido nervioso, que va hacia la igualación y la inercia, que Luria detectó en el centro de cada síntoma neuropsicológico, en un todo de acuerdo con las propuestas de Freud en el Proyecto (1950a) y Más allá del principio del placer (1920g).

La segunda parte (observaciones) pone en evidencia tanto el cuidado en el enfoque neurológico cuanto la sutileza del trabajo clínico con cada paciente. El cuidado en el estudio de las peculiaridades de cada paciente desde la perspectiva del caso único se halla además a tono con las tendencias recientes en la investigación clínica. Las descripciones clínicas son convincentes, y parecen responder a la tentativa de que resulte claramente comprensible tanto para los psicoanalistas cuanto para los neurólogos en lo referente a las perturbaciones involucradas. Quizá este otro rasgo positivo de los estudios clínicos sea a su vez el origen de un problema de otro orden, sobre el cual deseamos poner nuestro énfasis. Nos referimos al carácter asistemático de estas investigaciones clínicas. Entre lo varios aspectos que podemos mencionar al respecto, se advierten dos puntos centrales: 1) no resulta claro el criterio para el establecimiento de los diagnósticos psicopatológicos y, 2) falta un método de detección diferencial de las estructuras clínicas. Por ejemplo, no resulta preciso qué entienden los autores por psicosis, ya que las paranoias quedan ubicadas entre las neurosis narcisistas, mientras que más bien Freud (1924b) consideraba que solo las melancolías corresponden a este grupo. Pero sobre todo, coincidiendo con el comentario de Henltschel et al. (2004), advertimos la ausencia de un 
método sistemático para estudiar la clínica tomando la perspectiva de la defensa, que para Freud era fundamental en un enfoque de tipo diagnóstico y en la evaluación de los tratamientos. Para Freud, el estudio de las defensas por un lado permite captar la singularidad de cada caso y su inclusión, el menos transitoria, en un diagnóstico, y por otra parte permite investigar el funcionamiento yoico y su perturbación. Por ejemplo, la desmentida y la desestimación son defensas opuestas a la realidad y la instancia paterna (superyó), pero en el primer caso se conserva algo del contacto con la realidad, que solo se pretende refutar (como en el fetichismo), mientras que en el segundo (desestimación) dicho contacto se pierde de manera más o menos extrema (y en su lugar pueden aparecer alucinaciones y delirios). Existe quizá un mecanismo más radical que estos dos, que podríamos ligar con los conflictos y las defensas entre Eros y pulsión de muerte, es decir, entre una tendencia a la inercia, como también lo mencionan los Solms, y otra, opuesta, que procura mantener una energía de reserva, y que expresaría una alianza entre los dos sectores de Eros (libido y autoconservación). Esta defensa ha sido descripta por Mc Dougall (1991) y por Maldavsky $(1986,1995)$ como desestimación del afecto. Es una defensa especialmente eficaz en las patologías psicosomáticas, las adicciones, las accidentofilias, las neurosis postraumáticas y organizaciones psíquicas afines. Lo esencial de tal defensa es que conduce a perder la regulación de los procesos anímicos por el afecto, entendido como la cualidad básica, que está en el fundamento de la vida psíquica. Esta defensa parece tener un valor desactivador de ciertas estructuras que crean un nivel elemental de organización de la vida psíquica, y en consecuencia prevalecen las alteraciones somáticas.

Además de las defensas, existe un segundo concepto freudiano de gran importancia en cuanto al estudio diferencial de las estructuras clínicas. Se trata del concepto de fijación libidinal en alguna zona erógena, como las que Kaplan-Solms y Solms mencionan al final de su libro. Por ejemplo, Freud sostuvo que la fijación oral canibalista predomina en las melancolías, mientras que la organización sádico anal tendiente al control y el dominio del mundo predomina en las neurosis obsesivas. La combinación entre estos dos grandes grupos de conceptos (fijación pulsional, defensa) parece fundamental cuando intentamos investigar de un modo sistemático las situaciones clínicas.

Entre los casos con una lesión en la región perisilviana izquierda los autores incluyen ricos estudios clínicos de pacientes afásicos. Nuestro interés es también estudiar este tipo de problemas clínicos, pero con otro enfoque, complementario con el de los autores. Nos proponemos realizar un estudio clínico sistemático de una primera sesión de una paciente afásica, para lo cual aplicaremos al material clínico un método basado en las propuestas de Freud, y que está diseñado para la detección de fijaciones pulsionales y defensas. En consecuencia, no nos interesa mostrar los nexos entre el discurso del paciente afásico y el funcionamiento neuronal sino estudiar las manifestaciones desde una perspectiva estrictamente psicoanalítica y con un enfoque sistemático.

El trabajo comienza con una breve caracterización del método, seguida de la muestra y su análisis. El caso es especialmente llamativo, ya que combina una fuerte limitación expresiva verbal y una notable riqueza expresiva en los niveles paraverbal y gesticular, por lo cual se hace necesario un mayor refinamiento en el análisis. Finalmente, expondremos la discusión y las conclusiones.

\section{Breve presentación del algoritmo David Liberman (ADL)}

El método empleado para realizar estas investigaciones es el algoritmo David Liberman (ADL), diseñado para detectar fijaciones pulsionales y defensas en el discurso. El ADL toma en cuenta varios niveles de análisis: 1) relato, 2) actos del habla (frases y componentes paraverbales), 3) movimientos, 4) palabras. Tanto en el relato como en los actos del habla y los movimientos es posible detectar escenas. Las primeras son narradas, y las segundas se despliegan al hablar o hacer. El análisis de los relatos permite estudiar los conflictos extratransferenciales del paciente. El estudio de los actos del habla permite investigar la relación transferencial. El inventario de las fijaciones pulsionales que el ADL detecta incluye: libido intrasomática (LI); oral primaria (O1); sádico oral secundaria (O2); sádico anal primaria (A1); sádico anal secundaria (A2); fálico uretral (FU) y fálico genital (FG). Como se advierte, a las fijaciones pulsionales descriptas por Freud, le agregamos la 
libido intrasomática, que el creador del psicoanálisis menciona al aludir a que, inmediatamente después del nacimiento, ciertos órganos (corazón, pulmones) reciben una extraordinaria investidura narcisista (Freud, 1926d).

En cuanto a las defensas, es posible diferenciar entre las centrales y las complementarias. Las centrales pueden ser: 1) sublimación/creatividad/acorde a fines, 2) represión, 3) desmentida, 4) desestimación de la realidad y de la instancia paterna, 5) desestimación del afecto. Estas defensas pueden ser exitosas, fracasar, o ambas cosas. Solo las últimas cuatro son defensas patógenas. La represión predomina en las neurosis de transferencia. La desmentida, en los rasgos patológicos de carácter, sobre todo los de tipo narcisista, la desestimación de la realidad y de la instancia paterna, en las psicosis, y la desestimación del afecto (Maldavsky, 1992, 1995; Mc Dougall, 1989), en las patologías psicosomáticas y adictivas, en las traumatofilias y en las neurosis postraumáticas. Es posible inferir una fijación pulsional por el análisis de las escenas relatadas o desplegadas en sesión como actos del habla. Es posible inferir la defensa investigando la posición del hablante en las escenas que narra o que despliega al hablar. El método permite investigar los conflictos del paciente en los terrenos tanto transferencial cuanto extratransferencial (con padres, socios, hijos, etc.).

Para el análisis de las erogeneidades, el ADL dispone de varios instrumentos. El estudio de los relatos y los actos del habla (componentes verbales y paraverbales) y los movimientos se realiza apelando a grillas específicas, y el estudio de las palabras, recurriendo a un programa computarizado. Aquí consignamos a manera de recordatorio la grilla de las erogeneidades en los relatos (Tabla I). El análisis de las defensas se realiza recurriendo a un conjunto de instrucciones que tienen una secuencia definida. Algunas instrucciones permiten investigar la defensa en el nivel del relato y otras permiten su estudio en el nivel de los actos del habla y los movimientos (Maldavsky, 2003, Maldavsky et al., 2005).

El ADL arroja resultados multivariados: pueden coexistir varias erogeneidades y defensas eficaces, con el predominio transitorio o estable de alguna de ellas. Respecto de las defensas, el ADL está diseñado además para detectar su estado (exitoso, fracasado, etc.). Con los instrumentos del ADL (grillas, programa computarizado, secuencia de indicaciones) es posible analizar el discurso del paciente. Para estudiar el discurso del terapeuta, y sobre todo su eficacia sobre el paciente, fue necesario producir otro instrumento. Este consiste en diferenciar las intervenciones del terapeuta por su función. Estas pueden ser: 1) introductoria, 2) central, 3) complementaria. Es posible además investigar las secuencias de intervenciones del terapeuta para detectar si sus cambios son acordes con las modificaciones del discurso del paciente, y por lo tanto se mantiene la misma estrategia, o si, por el contrario, implican una rectificación, una modificación en la orientación clínica.

En esta oportunidad nos interesa usar el ADL para investigar tres niveles de análisis: 1) las relaciones extratransferenciales de la paciente, 2) las relaciones intrasesión, 3) el nexo pacienteterapeuta desde la perspectiva de la intersubjetividad, lo cual implica estudiar el destino dado para cada interlocutor a sus propias exigencias pulsionales y a las ajenas.

\section{Muestra}

Un año atrás Liliana sufrió un ACV seguido de un coma y de una internación de cuatro meses. Como consecuencia de ello quedó con una hemiplejía lateral derecha. Estaba en pareja con un hombre 20 años menor, quien asistió a la pre-entrevista acompañado de un hermano de Liliana. Ambos narraron que la paciente, que era contadora, sufría desde antes de hipertiroidismo y diabetes que nunca trató. Además fumaba mucho. En el accidente cerebro-vascular, luego de un estallido de furia por dificultades laborales, perdió el conocimiento mientras trabajaba en la casa, y la atención médica demoró un tiempo que les pareció muy largo. Hasta enfermarse la paciente participaba con entusiasmo como alumna de una escuela de teatro. Según manifestaron el novio y el hermano, están insatisfechos con el instituto en que Liliana se atiende, y la entrevista tiene por objetivo cambiar la institución de rehabilitación. 
2*1. En la entrevista el terapeuta comienza preguntándole el nombre y la paciente ríe, suspira y dice "Toalla, toalla". Esta secuencia tiene un matiz histriónico. El terapeuta insiste con la pregunta y la paciente, tras un silencio responde: "Tuschar, tuschar" con el mismo tono dramático. El terapeuta le pregunta si sabe por qué ella está en la entrevista. Ante el silencio de Liliana, opta por presentarse y hace referencia a la entrevista con la pareja y el hermano de Liliana, así como a la información que ellos le dieron sobre su accidente cerebral. Agrega que él quiere conocerla, saber cómo ella se siente con lo que le pasa y con lo que le ocurrió, con el objetivo de ayudarla. "Sí”, dice la paciente varias veces, y repite: "Toalla, toalla, ta, ta, ta, ta, ta, toalla, toalla, toalla". El terapeuta le pregunta: “Son muchos?” y la paciente responde, bajando el tono: “Toalla”. “Cinco”?, dice el terapeuta, y la paciente responde afirmativamente. El terapeuta dice que ella le está contando que estuvo mucho tiempo internada. “¿Cuatro meses?”, agrega el terapeuta, “¿Así?”, pregunta mostrando cuatro dedos de una de sus manos. "Así, así” (mostrando cuatro dedos de la mano izquierda), responde la paciente y agrega: "Toalla, toalla, toalla, toalla". El terapeuta prosigue diciéndole que ella no podía mover la mano, el brazo, la pierna, nada". "Toalla" responde la paciente con pesar. "Nada" repite el terapeuta y la paciente también dice "Nada".

2. El terapeuta la pregunta si siente tristeza o enojo. "Toalla", responde la paciente con voz más firme. El terapeuta dice que ella tenía rabia y golpea el escritorio con la mano. Liliana asiente: "Sí" y golpea también el escritorio con la mano izquierda. Ambos golpean y Liliana sonríe. El terapeuta agrega que quizás ella no entendía lo que le pasaba. "Toalla", responde la paciente y el terapeuta insiste: ella no entendía qué pasaba con su cuerpo. La paciente parece aceptar con un gruñido. Tras un silencio el terapeuta le preguntó qué le pasó cuando se empezó a dar cuenta que no podía mover el brazo. La paciente emite un gruñido que el terapeuta repite. El terapeuta le dice que quizás se sintió perdida, y la paciente responde afirmativamente. "Toalla, toalla", exclama con vehemencia, "toalla, toalla". "Todos hablando..." comenta el terapeuta. La paciente asiente y dice: "Ta, ta, ta, ta, ta, ta, ta, ta”.

3. El terapeuta pregunta quiénes eran todos. "Toalla" responde la paciente, con un tono de que era obvio quienes hablaban. "Ta, ta, ta, ta, ta, ta”, agrega. El terapeuta dice: “EEl médico que tardaba?" "Toalla, toalla", responde Liliana con tono afirmativo. "O sea, que llamaban y llamaban y no venían”. La paciente asiente levantando el brazo izquierdo. El terapeuta dice: "Nos vamos entendiendo" y agrega que para ella es un alivio cuando alguien la puede entender y que le da rabia cuando no la entienden.

4. Luego, el terapeuta propone volver al relato y le dice que Liliana estaba trabajando cuando tuvo el ataque. "Escribiendo" agrega, y Liliana realiza algunos ruidos sordos, rítmicos: "Tu, tu, tu". Tras un silencio prosigue diciéndole que entonces tuvo el ataque. "Toalla, to toalla, toalla, toalla”, dice la paciente gesticulando. El terapeuta le dice que ella estaba pagando y luego, en una semi-rectificación, agrega que ella estaba con dinero. La paciente responde afirmando. El terapeuta le pregunta si ella cayó al piso y la paciente emite un sonido largo, grave que el terapeuta imita. La paciente ríe y el terapeuta vuelve a imitar el sonido que parece dramatizar una escena de un cuerpo caído, desfalleciendo. El terapeuta prosigue diciendo que entonces llamaron a los médicos, que no venían. El terapeuta le pregunta si ella se ponía más nerviosa y Liliana asiente gruñendo y repitiendo "Toalla, ta, ta, ta”. Luego agrega " ¡Pa!” y el terapeuta descifra: "Cinco”. La paciente afirma e insiste: "†Toalla, toalla, toalla!". El terapeuta dice que entonces apareció la ambulancia ("Toalla", dice Liliana como asintiendo con su tono de voz) y la llevaron al sanatorio. Le pregunta si siempre estuvo con los ojos abiertos. La paciente responde: "Toalla" y hace el gesto de estar desfalleciendo (bajando los brazos) y el terapeuta concluye que estuvo así, desfalleciendo, con los ojos abiertos. El terapeuta le pregunta si recuerda cuando estuvo internada y la paciente dice: "No". "Toalla", repite la paciente y se toca la nariz. El terapeuta dice: "Ah, pero se acuerda de cuando le pusieron el suero". La paciente responde asintiendo. El terapeuta le dice que le pusieron cosas por todos lados, en la nariz, como ella le muestra en ese momento. Mientras, la paciente repite: "Toalla".

2 * La fragmentación de la sesión tiene como criterio el cambio en las intervenciones del terapeuta y la correspondiente respuesta de la paciente. Esta fragmentación pretende facilitar el análisis de las escenas desplegadas en la sesión. 
5. El terapeuta le pregunta si ella se sintió asustada en ese momento, y la paciente responde con tono más enérgico: “Toalla”. “¿No?”, le pregunta el terapeuta, y la paciente responde: "No”. El terapeuta le pregunta si ella nunca tuvo miedo y Liliana responde: "No". El terapeuta le dice que ella es testaruda y la paciente lo admite con sonidos de aceptación. "Toalla", dice con voz suave.

6. El terapeuta le pregunta si estaba su pareja con ella y Liliana asiente. El terapeuta comenta que él la acompaña mucho. "Toalla", dice Liliana asintiendo, y gruñe largamente. El terapeuta la imita y le pregunta qué quiere decir eso. "Toalla”, responde Liliana. Muestra cinco dedos de su mano derecha.

7. El terapeuta le pregunta por qué ella dice "toalla” y muestra los cinco dedos. La paciente ríe abiertamente. El terapeuta repite "Toalla, toalla". La paciente sigue riendo. El terapeuta le dice que el hermano y la pareja de Liliana le comentaron que ella hacía teatro, le pregunta si es teatro para chicos o para grandes. La paciente responde "Toalla". Murmura: "Tuca, tusta". El terapeuta pregunta qué es "Tusta". "Toalla", responde Liliana, gruñendo, y se señala la boca. El terapeuta le pregunta si alude a un golpe en la boca y la paciente responde con sonidos graves.

8. El terapeuta le pregunta qué extraña de antes. Tras un silencio, Liliana comienza a llorar. El terapeuta le dice: “Aparece el dolor". Y, tras un momento, le pregunta si ella llora a menudo. La paciente dice que no. El terapeuta le pregunta si antes lloraba y la paciente sigue llorando. El terapeuta le dice que parece que no le gusta que la vean llorar, que quiere estar sola. Liliana asiente.

9. El terapeuta le dice que ella está empezando con las evaluaciones y los tratamientos para ver cómo recuperarse de su situación, poder hablar un poco mejor, caminar con más seguridad. Liliana asiente. El terapeuta le pregunta cómo se siente en otra institución donde se hace la rehabilitación. "Toalla", responde la paciente, y el terapeuta pregunta si le gusta ir. La paciente dice que no. El terapeuta le pregunta por qué no le gusta y la paciente reitera: "No, toalla", e insiste: "Toalla". Reitera "toalla", varias veces. El terapeuta le pregunta qué otras cosas hace en ese instituto y la paciente responde: "Toalla". El terapeuta le pregunta si ella quiere cambiar de lugar y Liliana asiente.

10. El terapeuta le pregunta qué hace ella en la casa. La paciente menciona un nombre y el terapeuta dice: "Está con la empleada". El terapeuta le pregunta qué hace (mira TV, escucha música, se acuesta). “Toalla”, responde la paciente. “¿Aburrida?”, le dice el terapeuta. "No hay nada para hacer". "Toalla, toalla, ta, ta, ta, nada, nada", responde la paciente. "Hay poco para hacer", concluye el terapeuta y le pregunta si los familiares la visitan. La paciente niega con la cabeza. El terapeuta le pregunta cómo se llaman sus hermanos. "Toalla, na na na na na", repite Liliana con una especie de melodía en las sílabas repetidas. El terapeuta le pregunta por su madre. "Bien”, responde la paciente. El terapeuta pasa a nombrar a los hermanos de la paciente (que tiene anotados) y le pregunta cómo se lleva con cada uno. La paciente dice, con gestos que el terapeuta descifra, que con un hermano se lleva más o menos, y con el otro, "bien". "Toalla", repite la paciente. El terapeuta le pregunta por la relación con el novio y Liliana insiste: "Toalla". El terapeuta le pregunta si él la cuida y ella asiente. El terapeuta le pregunta si trabajaban juntos en el estudio contable "¡Ah!”, dice Liliana y el terapeuta comenta: “Se acordó, ¿¿no?”. El terapeuta le pregunta que hacía él allí y la paciente responde: "Toalla", y luego repite, en voz más baja: "Toalla, toalla".

11. El terapeuta le pregunta cómo se siente con él en la entrevista. "Bien”, dice la paciente. "Toalla, toalla", repite.

12. Tras un silencio, el terapeuta le pregunta si ella tiene amigos, si vienen a visitarla. Liliana asiente. El terapeuta le pregunta si son colegas de ella y Liliana responde que sí. "Adriana”, dice la paciente y el terapeuta dice: "Salió un nombre, salió un nombre: Adriana”. "Liliana”, agrega la paciente. El terapeuta le dice que al comienzo de la entrevista no le salía el propio nombre. "Liliana”, repite la paciente, riendo. El terapeuta le dice: “su nombre, mire qué bien””. "Liliana, Liliana”, repite la paciente. El terapeuta le dice: "Tenemos que encontrar a Liliana, está muy lejos, pero salió el nombre". Le pide a la paciente que lo repita, y esta, llorando, dice "Liliana”. El terapeuta le dice que tal vez hace mucho que no lo pronuncia. El terapeuta le dice "qué fuerte que es nombrarse", mientras Liliana llora. 
13. El terapeuta agrega que dejó de decir "Toalla, toalla" (la paciente ríe) para decir "Liliana, Liliana”. "Liliana”, repite la paciente. El terapeuta le dice que hay que seguir buscando a Liliana, que está dentro de ella y que van a tratar entre todos de encontrar a Liliana, y que la paciente va a tener que ayudar mucho para eso, colaborar con los tratamientos. Ella tiene que trabajar sobre ella misma, sobre el cuerpo, las emociones, las palabras, que están metidas en ella y hay que sacarlas. También van a ayudar a su familia, porque esto le pasó a todos. "Sí", dice la paciente, y el terapeuta le dice que pasaron emociones muy fuertes en el encuentro juntos. Agrega que tras un momento, la verán otros profesionales para evaluarla en otras áreas. "Toalla" dice la paciente. El terapeuta dice: “Apareció toalla otra vez”. La paciente ríe.

14. El terapeuta le pregunta si le quiere decir algo más antes de terminar. "Toalla" responde la paciente. El terapeuta le pregunta cómo se sintió en la entrevista. "Bien”, dice la paciente. El terapeuta le pregunta por qué y la paciente responde: "Toalla, toalla". La paciente llora y el terapeuta le pregunta si está triste o emocionada. "Toalla", reitera la paciente varias veces y el terapeuta la saluda. Luego de la entrevista el terapeuta encuentra a Liliana en un pasillo y ella le tira un beso con los labios y la mano. Se muestra tierna y agradecida.

\section{Análisis}

\section{1. Análisis del discurso de la paciente}

Comencemos por un comentario general. Liliana no logra desarrollar un solo relato (aunque con la ayuda del terapeuta puede expresar uno, que luego estudiaremos), de modo que nuestro análisis solo puede centrarse en las escenas desplegadas durante la sesión. La paciente compensa la imposibilidad de narrar con un llamativo despliegue expresivo ante el terapeuta. Por un lado, dice unas pocas palabras repetidas, por otro lado la línea melódica con que las dice adquiere alto valor comunicativo, y por fin están sus gestos y movimientos.

En cuanto a las palabras sobresalen dos: "Toalla" y "Liliana". La primera corresponde a FG. El análisis de los actos del habla (en el nivel verbal) resulta dificultoso por el hecho de que la paciente solo emite palabras, las cuales constituyen frases. Algunas son repeticiones de las palabras del terapeuta ("Nada”, por ejemplo), y otras son acuerdos con lo que el terapeuta dice: "Sí". Ambas expresan FG. Otras palabras (entendidas como actos del habla), como "Bien", son respuestas de la paciente a preguntas del terapeuta referentes a cómo ella se siente, y expresan O2. En cuanto a los componentes paraverbales, destacan algunas onomatopeyas y una entonación histriónica con claras modulaciones melódicas. Ambos rasgos también pertenecen a FG.

El histrionismo también se hace presente en su gesticulación expresiva, con la cual pretende comunicar algo. Este rasgo corresponde a FG, y se combina con las manifestaciones de rabia (golpear la mesa) expresivas de A1, y con un gesto insistente de mostrar la mano abierta con los cinco dedos desplegados, el cual quizá sea no solo un esfuerzo de comunicar histriónicamente algo sino también un acto de descarga (LI).

Vista la sesión en su conjunto, las escenas desplegadas por la paciente parecen expresar su lucha por responder a la pregunta inicial del terapeuta por su propio nombre, hasta que finalmente logra pronunciarlo. La escena global va desde la impotencia nominativa (A2 y FG y defensa fracasada acorde a fines) hasta la pronunciación de su propio nombre (A2 y FG y defensa exitosa acorde a fines).

Consideremos ahora en detalle las manifestaciones de Liliana a lo largo de los fragmentos de la sesión. Nuestro objetivo inicial es detectar las escenas que despliega y sus cambios.

En el fragmento 1 advertimos la repetición (FG) de una misma palabra. El pasaje de "Toalla" repetido a "Tushar" parece derivar de que el terapeuta repite una pregunta (por el nombre de la paciente) que la entrevistada no puede responder. La jerga desaparece cuando el terapeuta le dice que desea saber qué le pasó y cómo se siente. Las afirmaciones reiteradas (FG) de la paciente son 
seguidas de otras repeticiones, sonidos onomatopéyicos y ademanes que el terapeuta intenta descifrar como relato. Ocurre entonces la primera repetición de una palabra del terapeuta por la paciente (“Así'). Tanto el acto del habla correspondiente (repetición de la palabra del interlocutor) cuanto el tipo de palabra-frase que la paciente repite (“Así”) tienen un valor FG. Los gestos de la paciente, que imitan a los del terapeuta, también corresponden a FG. El terapeuta prosigue el desciframiento del relato contenido en los movimientos y los componentes paraverbales de la paciente y entonces ocurre la siguiente repetición ("Nada"), que como acto del habla tiene un valor FG (imitación) y, como palabra, un valor LI.

Tras esta peculiar forma de contacto y recolección inicial de información del fragmento 1, en el fragmento 2 la paciente responde afirmativamente (FG) cuando el terapeuta le pregunta si siente rabia. La repetición de la paciente de los golpes que da el terapeuta reúne A1 (expresión de hostilidad) y FG (imitación), con un predominio de FG. La sonrisa también corresponde a FG. Además, Liliana responde con un tono de voz afirmativo y un gruñido y luego con un "Sí" (todo ello con un valor FG) a medida que el terapeuta se orienta para describirle su estado (perdida) en el momento del ataque y al salir de él.

En el fragmento 3 el terapeuta intenta reconstruir el momento en que esperaban la llegada del médico que se demoraba, acompañado por Liliana, quien utiliza la palabra "Toalla", el "Ta, ta, ta" y gestos o verbalizaciones de aceptación (FG).

En el fragmento 4 el terapeuta intenta reconstruir el estado previo al ataque y, basado en algunos gestos de la paciente, realiza una rectificación parcial de una afirmación previa. Cuando el terapeuta describe la caída de la paciente al piso, Liliana emite un gruñido largo que parece dramatizar un cuerpo desfalleciente. Con los mismos recursos y un gesto la paciente contribuye para que el terapeuta describa el momento de ser trasladada a la ambulancia y el suero. Tales recursos corresponden a FG, aunque la escena dramatizada expresa LI. En cambio, Liliana responde con un "No" a la pregunta acerca de si recordaba la internación.

En el fragmento 5 la paciente rechaza con su tono de voz haber sentido miedo, y acepta un rasgo de carácter que le adjudica el terapeuta: testaruda. La negación respecto de haber sentido angustia corresponde a A2, lo cual le permite al terapeuta aludir a su rasgo de carácter (testaruda). Este rasgo de carácter también corresponde a A2. La aceptación de la paciente de dicho rasgo corresponde a FG. En la escena narrada (por el terapeuta pero aceptada por la paciente), la testarudez se combina con la ausencia de afectos (LI).

En el fragmento 6, cuando el terapeuta le pregunta por su relación de pareja, la paciente responde "Toalla" y el gesto de la mano con los cinco dedos abiertos, es decir, con menos riqueza de recursos expresivos que antes. También en esta oportunidad la escena desplegada es FG, pero no se advierte qué relata con ella.

En el fragmento 7, en que el terapeuta le pregunta por el significado de "Toalla" y el gesto de la mano abierta, la paciente ríe y prosigue haciéndolo cuando el terapeuta la imita. En este fragmento, la escena desplegada es FG. Cuando el terapeuta le pregunta si hacía teatro para niños o para adultos Liliana recurre otra vez a neologismos ("Tuca, tusta") cuyo significado pretende aclarar señalando su boca y, cuando el terapeuta descifra que recibió un golpe allí, la paciente asiente con sonidos graves. Los neologismos expresan una escena FG pero el relato acompañante (subrayado por los gestos) corresponden a una escena LI.

Cuando en el fragmento 8 el terapeuta le pregunta qué extraña de antes, la paciente llora. Luego, con gestos, aclara que no llora a menudo y que no le gusta que la vean llorar. La escena corresponde a O2, combinado con A2 (testarudez incipiente en la sesión).

En el fragmento 9, a través de la entonación de la voz y el “No”, la paciente expresa su desagrado respecto de una institución donde realiza rehabilitación y su deseo de dejarla. La escena corresponde a A2, en el marco de la toma de decisiones y el contrato de trabajo.

En el fragmento 10 la paciente responde con un nombre ininteligible a la pregunta acerca de 
lo que hace en la casa, que el terapeuta descifra como una alusión a que está con la empleada. Luego, tras la palabra "Toalla" y "Ta" repetidos, reitera también la palabra "Nada", que dijo antes el terapeuta ("No hay nada para hacer"). Luego la paciente, con gestos de la cabeza o de la mano, responde a preguntas acerca de los familiares que la visitan, así como a su relación con su madre ("Bien", responde Liliana). Con todo ello pretende aportar la información solicitada por el terapeuta, como si se tratara de un relato condensado de escenas concretas (A2). Cuando el terapeuta menciona el lugar en que antes trabajaba con el novio, la paciente dice " $\mathrm{A}$ Ah!”, que el terapeuta descifra como una expresión de haberse acordado, aunque esta luego continúa con los "Toalla" cuando el terapeuta pregunta mayores precisiones. El aludir al hecho de recordar es una expresión de una escena A2.

En el fragmento 11 la paciente responde con un "Bien” a la pregunta sobre cómo se siente en la entrevista. La respuesta corresponde a $\mathrm{O} 2$.

En el fragmento 12 la paciente responde con gestos a la pregunta acerca de si la visitan amigos, que son colegas. Entonces profiere el primer nombre comprensible ("Adriana") y luego dice el suyo propio, hecho que el terapeuta destaca. Riendo, la paciente repite su propio nombre, estimulada por el terapeuta. El decir su propio nombre y repetirlo corresponde a una escena desplegada FG.

Al comienzo del fragmento 13 la paciente aún insiste en decir su nombre y ríe ante un comentario del terapeuta (acerca del cambio de "Toalla" a "Liliana"). A ello agrega un "Sí" cuando el terapeuta la exhorta a continuar el tratamiento, pero vuelve a "Toalla" cuando este alude a que será evaluada por otros profesionales. Como el terapeuta le señala la reaparición de "Toalla", Liliana ríe. La risa y la repetición de palabras corresponde a FG pero el volver a "Toalla" contiene algo del enojo (A1) por el próximo abandono por el terapeuta.

En el fragmento 14 Liliana insiste con "Toalla" cuando el terapeuta le propone si quiere decir algo más. Cuando este le pregunta cómo se sintió durante la entrevista, Liliana repite que se siente "Bien", pero vuelve al "Toalla" cuando el terapeuta le pregunta por qué. En este último fragmento alternan manifestaciones de estados afectivos (O2) y de enojo vengativo (A1). La sesión termina con una escena FG (beso soplado).

A partir del estudio de las escenas desarrolladas por la paciente en la sesión es posible dar un nuevo paso, consistente en analizar los cambios que se dieron a lo largo de la hora. Es posible distinguir al menos cuatro momentos: 1) fragmentos 1-4, 2) fragmentos 5-7, 3) fragmentos 8-10, 4) fragmentos 11-14. El primer fragmento se caracteriza por la tentativa del terapeuta de establecer el contacto y de recabar información, e incluye un primer intento (exitoso) del terapeuta de sintonía afectiva (fragmento 2), sobre todo en torno del enojo de la paciente. El segundo es el que muestra más claramente las dificultades clínicas del caso: el terapeuta ya no puede aportar más escenas de la historia de la paciente e intenta una segunda sintonía afectiva (en torno del miedo), que fracasa, y que lo lleva a aludir a la testarudez de la paciente. En la tentativa de hallar un camino clínico el terapeuta alude a la actividad teatral de la paciente antes del accidente, pero fracasa al pretender obtener mayores detalles. La paciente le propone una salida: hace referencia a otra parte del accidente (golpe en la boca). En el tercer momento, el terapeuta ya no pregunta por un estado afectivo sino por lo que Liliana extraña de su vida anterior al accidente, y la paciente prorrumpe en llanto, con el cual casi en seguida entra en conflicto. El terapeuta avanza en la formalización del contrato y luego intenta que la paciente le narre su actividad actual (en el instituto de rehabilitación, en su hogar, con la familia y con la pareja). La paciente puede proferir el nombre de la empleada de servicio que la cuida y luego parece recordar el trabajo que antes hacía junto con su pareja. En el cuarto momento, tras una nueva tentativa (exitosa) del terapeuta de sintonizar con la paciente (esta vez referida al vínculo con el terapeuta mismo en ese momento), le pregunta por la relación con amigos, y Liliana puede pronunciar el nombre de una y el propio. Sin embargo, vuelve transitoriamente a su abroquelamiento en "Toalla" cuando el terapeuta alude al cierre de la entrevista. Tras una nueva tentativa (exitosa) de sintonizar con la paciente, en relación con cómo se sintió durante la entrevista que termina, Liliana manifiesta casi simultáneamente un estado afectivo (llanto) y una posición más testaruda, pero sobre todo agradecida y tierna. 
En el primer momento el vínculo se vio favorecido porque el terapeuta aportó la información que le dieron previamente el hermano y la pareja de la paciente, así que el problema de la testarudez y la falta de información se presentó sobre todo en el segundo momento. Pese a ello, la paciente orientó al terapeuta para que este construyera una escena (golpe en la boca). En el tercer momento se dan oscilaciones en cuanto al incremento o la disminución del rasgo de carácter (testarudez), con momentos en que este disminuye su peso en favor de la expresión del afecto y de palabras. La paciente parecía esperar la iniciativa del terapeuta para poder a su vez desarrollar sus propias manifestaciones, aunque solo lo orientaba parcialmente (sobre todo en el momento crítico, cuando se señaló la boca). Cuando el terapeuta halló el camino para la conexión, finalmente la paciente encontró la palabra faltante, referida a su propio nombre.

Consideremos ahora el repertorio de recursos expresivos de la paciente y su función. En cuanto a los componentes paraverbales, el más permanente es el tono de voz, muy variado e indicador de escenas precisas, del mismo modo que su timbre (FG). A ello se agregan gruñidos (A1), igualmente expresivos, quizá indicadores también de su testarudez. La risa y el llanto son francos, expresan estados afectivos ante el terapeuta. La risa aparece al sentirse percibida e incluso imitada por el terapeuta, y el llanto es sobre todo la expresión de un estado de tristeza (fragmento 8), o del surgimiento de la emoción (fragmento 12 y 14). Estas últimas manifestaciones paraverbales corresponden a $\mathrm{O} 2$ y FG y defensa acorde a fines exitosa.

En el terreno verbal, la escena que unifica la sesión (responder a la pregunta del terapeuta por su propio nombre) corresponde a A2 y FG en versión eufórica. Pero durante buena parte de la hora el nombre de la paciente no estuvo disponible, lo cual corresponde a A2 y FG y la defensa acorde a fines fracasada.

Durante ese extenso período de la sesión (hasta el fragmento 12) la paciente intentó sustituir la ausencia nominativa con gestos, modulaciones tonales, y otros tipos de sonidos, y unos pocos monosílabos que permitieron al terapeuta inferir y construir ciertas escenas del pasado reciente de Liliana. Estos recursos expresivos que suplen la ausencia nominativa son básicamente FG.

Consideremos ahora las palabras o equivalentes. Algunas son insistentes, como "Toalla", "Ta", "Na", y parecen corresponder a FG. Otras son respuestas monosilábicas: "No", "Sí", "Bien”, ante preguntas del terapeuta. Otras son repeticiones de palabras del terapeuta (“Así”, "Nada”), otras son onomatopeyas ("Pa", "Tu") y otras son neologismos. Estos últimos aparecen en los fragmentos 1 ("Tuscher") y 7 ("Tuca"). Parecen ser respuestas frente a preguntas demasiado exigentes para las posibilidades de la paciente. Como el resto del discurso de la paciente, el neologismo posee un rasgo histriónico, pero carece de significatividad convencional.

En cambio, "Toalla" aparece cuando la paciente debe refugiarse en su rasgo de carácter (testarudez), como ocurre al final de la hora, en el momento en que el terapeuta le menciona que será entrevistada por otros profesionales. Pese a ello "Toalla" también tiene un componente histriónico, expresado más bien por los componentes paraverbales y los movimientos de la paciente. De modo que simultáneamente Liliana expresa la testarudez en el nivel verbal y defensas funcionales en los niveles paraverbales y gesticulares.

Más allá del inventario que hemos expuesto poco antes, es conveniente prestar atención a la función de los diferentes grupos de palabras que Liliana empleaba. El grupo más importante (toalla, ta, algunas onomatopeyas, los gruñidos, la línea melódica) forma parte del núcleo de sus recursos expresivos dominantes. Otros (neologismos) corresponden a una regresión mayor, a una pérdida transitoria del lenguaje consensual, y otros (su nombre y el de su amiga) son, por el contrario, un avance más complejo desde su grupo más permanente y estereotipado de recursos.

La paciente regresa a formas expresivas más elementales (desde los recursos más frecuentes a los neologismos o desde el lenguaje más diferenciado, en que puede nombrarse, al grupo de recursos más frecuente) ante las amenazas de decepción, sea porque el terapeuta le hace preguntas que no puede responder, sea porque le anuncia que pasarán a entrevistarla otros profesionales. La regresión a formas expresivas más elementales afecta a A2 y la defensa acorde a fines, porque se incrementa 
en la paciente la ausencia nominativa. En cambio, no afecta a FG, ya que en todo momento mantiene la actitud histriónica.

La versión disfórica de A2 en los actos del habla se acompaña con versiones disfóricas de LI a través de lo que relata. También en los actos del habla la ausencia nominativa parecería ser una presentificación del trauma (LI y desestimación fracasada del afecto). Sin embargo, la paciente apelaba a recursos histriónicos FG (gestos, línea melódica, etc.) compensatorios, que resultaban exitosos. Estos recursos consistían en dramatizaciones, solo que no incluían frases de otros que la paciente repetía sino componentes paraverbales y gesticulares. Estos componentes suelen aparecer como complemento en numerosas dramatizaciones, y acompañar al discurso verbal, al cual enriquece, mientras que en esta oportunidad constituyen el núcleo expresivo de la paciente. Las escenas en que la paciente apela a la misma palabra ("Toalla") acompañada en cada ocasión de diferentes gestos y entonaciones se asemejan a esos ejercicios teatrales en que intencionalmente se repite una palabra neutra con variaciones gesticulares y paraverbales que le dan el verdadero matiz significativo al conjunto.

En cuanto a "Toalla", ya destacamos que, como palabra (y no como acto del habla), expresa FG. Además, como acto del habla tiene el valor de una condensación de un relato, es decir una condensación de múltiples escenas y significatividades que requieren de un despliegue narrativo a lo largo de las sesiones. Es el testimonio de la formación verbal con la cual la paciente intentó responder a la vivencia traumática.

En cuanto al llanto de emoción que aparece en los fragmentos 12 y 14, parece indicar no tanto el fracaso de la desestimación del afecto (ya que en ese caso el llanto sería por angustia). Se trata más bien del llanto por remoción parcial de la defensa patógena (desestimación del afecto) y su sustitución por una defensa funcional inherente a O2. Algo parcialmente diferente ocurre en el fragmento 8, cuando la paciente interfiere su propio llanto, ya que prefiere llorar en soledad. En ese momento un levantamiento parcial de la defensa quedó neutralizado por un incremento de ella. Así, pues, hubo dos momentos en que la desestimación del afecto fue removida. En el primer momento el cambio fue solo transitorio. En el segundo, se sostuvo hasta el final de la hora.

En cuanto a la estructura de la paciente es posible diferenciar dos corrientes psíquicas. Una de ellas parece organizarse en torno de un rasgo caracterológico (testaruda) como defensa ante el trauma. Este rasgo caracterológico también le permitía a la paciente defenderse (vengativamente) de la vivencia de despecho por el abandono, lo cual corresponde a A1 y la desmentida exitosa. Pero al mismo tiempo la preservaba del retorno de las vivencias de apatía o de angustia tóxica. Por tal hecho, "toalla" expresa también a LI y la desestimación exitosa del afecto. Este sistema defensivo había fracasado en el momento del ataque, pero en el momento de la sesión, sobre todo en la primera parte, era exitoso. Sin embargo, el apego a este único término ("toalla") dejaba a la paciente ante el riesgo de la ausencia nominativa, como de hecho ocurrió cuando en el comienzo de la hora no pudo decir su propio nombre. La paciente neutralizaba en buena medida dicho riesgo apelando a la otra corriente psíquica. Esta se expresaba básicamente en los niveles paraverbales y gesticulares, en los que predominaba FG y $\mathrm{O} 2$ y la defensa acorde a fines. Además los componentes gesticulares y paraverbales podían tener también un valor catártico (LI y desestimación exitosa del afecto), aunque en el conjunto predomina FG. Así, pues, una corriente psíquica combinaba A2 + rasgos caracterológicos, A1 y desmentida y LI y desestimación del afecto, y en la otra prevalecían O2, FG y la defensa acorde a fines. En el tratamiento se dio una permanente combinación entre estas dos corrientes, con un predominio de la centrada en el rasgo de carácter (momento segundo de la sesión) o de la centrada en las defensas funcionales (cuarto momento de la sesión). La relación entre ambas corrientes psíquicas podría implicar que Liliana usaba $\mathrm{O} 2$ y FG (componentes paraverbales y gesticulares) para desmentir sus limitaciones expresivas verbales, pero en los hechos esta alternativa no se dio, aunque tal vez algo de ello apareciera en el fragmento 6 (segundo momento de la sesión, el más resistencial). Vista la situación en su conjunto se trata de una curiosa situación de coexistencia entre corrientes psíquicas y quizá más bien de complemento, en que una cara de la moneda es el rasgo caracterológico y la otra la solución expresiva. En sesión, en cambio, prevalecieron defensas funcionales y la desestimación exitosa del afecto, luego sustituida por otras defensas funcionales. 
Hacia el final de la hora, el hecho de recordar y proferir su propio nombre pone en evidencia un cambio en las defensas de Liliana. LI y la desestimación fracasada del afecto (en el nivel de los actos del habla) y LI y la desestimación exitosa del afecto (en los componentes paraverbales y motrices) es reemplazada por O2, A2 y FG, y la defensa exitosa acorde a fines (llanto de tristeza y luego llanto de emoción). En un comienzo (llanto de tristeza) en la paciente ocurrió un breve cambio en la defensa, y Liliana entró en conflicto con la escena paraverbal de expresión del afecto, quizá con la vivencia de que había sufrido un exceso de estimulación por el terapeuta. Pero luego (llanto de emoción) la expresión del afecto, inherente a $\mathrm{O} 2$ y defensas acorde a fines, no suscitó en Liliana el mismo conflicto, tal vez porque entre una y otra escena pudo pronunciar su propio nombre.

Hacia el final de la hora hubo una alternancia entre LI y desestimación del afecto (cuando reapareció "toalla") y $\mathrm{O} 2$ y la defensa exitosa acorde a fines (llanto de emoción), con un predominio de $\mathrm{O} 2$.

El análisis de la estructura psíquica de la paciente incluye LI y la desestimación del afecto, A2 y FG y la defensa fracasada acorde a fines. Posiblemente A2 y FG se combinan también con represión + defensas caracterológicas en el rasgo de testarudez. El final de la hora, cuando la paciente reemplaza temporariamente "Liliana” por "toalla” ante la próxima separación del terapeuta, muestra que su orgullo herido y su enojo (A1 y desmentida), así como la vivencia de desamor (O2 y desmentida), constituyen una fuente estimulante de la testarudez. Es posible que esta combinación entre LI y desestimación del afecto, $\mathrm{O} 2$ y A1 y desmentida y A2 y FG conectada con rasgos caracterológicos conforman la estructura patógena inicial de la paciente. Esta estructura se complementaba con A2 y la defensa acorde a fines exitosa. Las fallas en este sistema defensivo patógeno produjeron primero la diabetes y el hipertiroidismo. Luego del ACV, A2 se combinó además con la defensa acorde a fines fracasada, y se acentuó una escisión entre un fragmento en el cual tenía vigencia la falta de recursos psíquicos (en el terreno verbal) y otro en el que dichos recursos se mantenían de manera hipertrófica y compensatoria (en el terreno paraverbal y gesticular). Tal hipertrofia parecía además tener el valor de una desmentida de las limitaciones expresivas verbales. La defensa parecía exitosa y permitía que en la paciente se mantuviera también el éxito del sistema defensivo patógeno en su conjunto. Los estados de desvitalización que la paciente describió respecto del momento del ACV corresponden a la desestimación exitosa/fracasada del afecto, mientras que los accidentes orgánicos mismos expresan el fracaso de esta misma defensa. Pero tales estados de la defensa corresponden al nivel del relato y no al de los actos del habla de Liliana, en que el sistema defensivo patógeno era exitoso.

\section{IV.2. Análisis del discurso del terapeuta}

En el fragmento 1 el terapeuta intenta establecer el contacto y recabar información, para lo cual debe apelar tanto a lo que le dijeron la pareja y un hermano de la paciente cuanto a los gestos, los tonos de voz y los monosílabos de Liliana. Ya entonces recurre a la imitación de la paciente para establecer el contacto.

En el fragmento 2 pregunta por el estado afectivo de Liliana en el momento del accidente y luego de él. Recurre además a su propia motricidad (golpear el escritorio) para dramatizar el estado afectivo de la paciente.

En el fragmento 3, apelando a la misma información (relatos de la pareja y el hermano, gestos de Liliana, etc.), el terapeuta procura reconstruir el momento en que esperaban al médico, que se demoraba. Finalmente sostiene que están encontrando las vías del intercambio y afirma que esto es un alivio para Liliana.

En el fragmento 4, el terapeuta reconstruye con los mismos recursos el momento previo al accidente (en su estudio, trabajando) y sobre todo el momento en que Liliana cayó al piso, hasta ser trasladada en ambulancia. 
En el fragmento 5, le pregunta si estaba asustada y afirma que ella es testaruda.

En el fragmento 6 el terapeuta vuelve a recabar información acerca de si estaba su pareja en el momento del accidente y si este la acompañó.

Ante la reiteración de "Toalla" y la mano abierta de la paciente, en el fragmento 7 el terapeuta pregunta por el significado de ello, luego alude al teatro y le pregunta si ella hacía teatro, y luego le da dos opciones, al preguntarle si era teatro de niños o de adultos. Como la paciente responde con neologismos, le pregunta por su significado, y descifra (por los gestos de Liliana) que son la descripción de una escena. Claro que con ello alude más a los gestos que a los neologismos de Liliana.

En el fragmento 8 el terapeuta le pregunta qué extraña de antes y, ante la escena de la paciente en llanto, comenta que a ella no le gusta llorar frente a otros.

En el fragmento 9, el terapeuta describe a la paciente las evaluaciones que se realizarán en la institución y su finalidad, y le pregunta sobre su actividad en otra institución en la que se trata, y sobre la voluntad de la paciente de sustituirla por aquella en que consulta en ese momento.

En el fragmento 10 el terapeuta recaba información sobre las actividades de la paciente en su casa, donde no hay nada para hacer. Luego el terapeuta pregunta por los familiares que la visitan y por la pareja, con la que trabaja hace años en el estudio. Resalta entonces que ella recordó algo de esos momentos

Tras preguntarle brevemente cómo se siente la paciente con él en la entrevista (fragmento 11), en el fragmento 12 recaba información respecto de los amigos que la visitan. Como la paciente menciona el nombre de una amiga, el terapeuta lo destaca, y luego, cuando Liliana profiere su propio nombre, hace otro comentario respecto de la importancia de ese momento. Luego propone un proyecto de trabajo para que la paciente se reencuentre con su nombre y otras palabras y le solicita a Liliana que repita su propio nombre. Agrega que hace mucho que ella no lo pronuncia y que es muy fuerte nombrarse.

En el fragmento 13 el terapeuta describe el pasaje de "Toalla" a "Liliana" e insiste con la importancia del proyecto clínico para Liliana y su familia, ya que todos pasaron por la situación. Alude a las entrevistas de la paciente con otros profesionales y termina destacando que la paciente volvió a decir "Toalla” y preguntándole si su llanto era de emoción o de tristeza.

En el fragmento 14 le pregunta a Liliana si desea agregar algo más, y luego le pregunta cómo se sintió en la entrevista. Ante el "Bien" de la paciente, le pregunta por qué. Ante el llanto de Liliana, el terapeuta le pregunta si está triste o emocionada y finalmente la saluda.

Las intervenciones del terapeuta consisten en buena medida en tentativas de recabar información traduciendo gestos y componentes paraverbales de la paciente en relatos (fragmentos 1, 3, 4, 6, 7, 9 y 10). También recurre a esta traducción (ayudado por monosílabos de Liliana) para sintonizar afectivamente con ella (fragmentos 2, 4, 8, 11 y 14). Además, algunas de sus intervenciones establecen nexos causales (fragmento 3, 5, 8 y 12), contienen indicaciones (fragmentos 9 y 13) o comparaciones (fragmento 13) o consisten en preguntas a la paciente con dos opciones de respuesta (fragmentos 2, 7 y 14) o en preguntas tipo "por qué”. Entre las intervenciones del terapeuta, el contacto (FU) y el recabar información (A2) son de tipo introductorio, mientras que la referencia a los estados afectivos de la paciente (O2), el establecimiento de nexos y comparaciones y el dar indicaciones (A2) son intervenciones centrales. Las preguntas con dos opciones y el por qué constituyen intervenciones introductorias o complementarias. Además, el terapeuta repite la palabra usada por la paciente, "Toalla", así como sus gestos, lo cual corresponde a FG. Este recurso tiene una función complementaria al servicio de recabar información, sintonizar con la paciente o aludir a un nexo causal, etc.

Globalmente hablando, las intervenciones del terapeuta fueron exitosas, salvo en las dos ocasiones en que promovió transitoriamente una regresión parcial de la paciente por exigirle respuestas que esta no podía dar (fragmentos 1 y 7). Resulta notable advertir que las intervenciones 
menos pertinentes del terapeuta (por solicitar información que la paciente no puede dar, lo cual se evidencia inclusive cuando le pregunta si hacía teatro para adultos o para niños o si su estado es de tristeza o de emoción) son todas de tipo introductorio. El terapeuta compensaba ampliamente el empleo de intervenciones no pertinentes con otros dos recursos, muy ricos. El primero consistía en imitar a la paciente o ponerse a sí mismo como personaje para que ella lo imite. La segunda consistía en hallar nuevas preguntas para formular a la paciente, con el objetivo de establecer un diálogo más fluido. Mientras que en los momentos en que le pide información inaccesible para la paciente prevalecen A2 y la represión + defensas caracterológicas, en el resto de la sesión prevalecen la defensa acorde a fines y sobre todo la creatividad.

\section{IV.3. Las defensas patógenas exitosas de la paciente y las intervenciones del terapeuta}

Hemos destacado ya que el sistema defensivo patógeno de la paciente se mantuvo con éxito a lo largo de la hora y que hacia el final de la entrevista fue en parte removida y sustituida por defensas funcionales, con lo cual se dio la coexistencia entre dos corrientes psíquicas, una de las cuales correspondía a un fragmento en que predominaban mecanismos patógenos exitosos.

Durante la hora el terapeuta intentó mantener la sintonía afectiva con la paciente y se esforzó por establecer el relato de escenas a partir de la información no verbal y paraverbal de la paciente, lo cual requirió del empleo de sus propios recursos, FG y la creatividad para acceder finalmente a A2 (relatos, nexos causales, etc.).

También advertimos que en algunas ocasiones el terapeuta tenía intervenciones introductorias parcialmente no pertinentes, que luego rectificaba. Todas ellas correspondían a A2, sea para recibir información más precisa, sea para establecer nexos causales. Con estas intervenciones el terapeuta podía correr el riesgo de ocupar el lugar de un personaje en una escena traumatizante de la paciente.

Más allá de ello, cabe preguntarse si estas intervenciones del terapeuta no eran un efecto de la tentativa de conjurar un riesgo opuesto, consistente en que con sus intervenciones y su esfuerzo por emplear FG al servicio de A2 (relatos, etc.), el terapeuta convalidara el éxito de la defensa patógena de la paciente, al promover la ilusión de que no es necesario el lenguaje hablado para el intercambio y para el procesamiento interno. Sus intervenciones introductorias expresaban precisamente a A2, en la tentativa de recuperar la dimensión del lenguaje hablado y su valor en la vida psíquica, y en este sentido podía ser la expresión de la tendencia del terapeuta a cuestionar un tipo de alianza resistencial con la paciente basada en apelar a sus recursos expresivos para mantener el éxito de una desmentida patógena.

\section{Discusión}

\section{Sobre la autodenominanción, la representación y el pensamiento inconscientes}

En el texto sobre las afasias, Freud (1891b) se refirió a dos sectores representacionales, las representaciones-cosa y las representaciones-palabra. Ambos compuestos son diferentes. La representación-palabra contiene el acervo cultural humano, y constituye un conjunto cerrado en el cual se combinan cuatro componentes, dos de ellos sensoriales (la imagen sonora de la palabra oída, la imagen visual de la palabra escrita) y los otros dos, motrices (la imagen de los movimientos para repetir la palabra oída, la imagen de los movimientos para repetir la palabra escrita). En cuanto a las representaciones-cosa, conforman un conjunto abierto, constituido por los recuerdos de vivencias (que incluyen elementos táctiles, motrices, olfatorios, visuales). Entre los componentes de la representación-palabra, el central es la imagen sonora y entre los elementos de la representacióncosa lo es la visual. El nexo entre estos dos componentes (una imagen sonora y otra visual) es el modo de enlace entre ambas representaciones. 
Es posible comparar los resultados de nuestro análisis clínico con este enfoque temprano de Freud respecto del aparato del lenguaje. Un aspecto central parece consistir en la perturbación en ese sector de la representación-palabra, la ligada al componente motriz. La paciente parece entender la palabra oída, pero no puede repetirla. En este punto la paciente se asemeja a un caso descripto por Kaplan-Solms y Solms (2000). Pero lo central del sufrimiento de la paciente parece no ser tanto la imposibilidad de referirse a las "cosas del mundo", cuanto el no poder nombrarse. Con ello quiero decir que es conveniente diferenciar entre dos sectores de las representaciones que se combinan con las representaciones-palabra. Uno de tales sectores es la representación-cosa y el otro podría ser denominado representación-yo o representación-cuerpo. Por supuesto, entre ambos sectores (representación-cosa, representación-cuerpo) se dan múltiples nexos, e inclusive ocurre que ambos se superponen. Algo de esta dinámica entre ambos sectores se advierte en el hecho de que la paciente solo puede proferir su propio nombre luego de mencionar el de Adriana, su amiga. Una escena similar se da durante la sesión, cuando el terapeuta imita los sonidos y los movimientos de la paciente, y cuando esta repite las palabras o los gestos del terapeuta. Entre el otro y el yo se dan procesos identificatorios. Nombrarse y nombrar a otro pueden ser procesos de presuposición recíproca.

Es posible avanzar en la tentativa de dar mayor especificidad a nuestro estudio. Desde el punto de vista del desarrollo psíquico y del lenguaje, un niño comienza profiriendo holofrases, es decir, palabras que contienen múltiples significados antes de que estos alcancen mayor diferenciación. Lo condensado en tales frases puede contener componentes diversos. A veces son estados de tensión orgánica, o de vértigo, etc., lo cual corresponde a LI. Otras veces los contenidos pueden ser pensamientos veloces, habitualmente violentos, catastróficos, lo cual corresponde a $\mathrm{O} 1$. También pueden darse condensaciones de estados afectivos, como es inherente a O2. Finalmente, pueden condensarse sonidos con el valor de acciones de tipo vengativo, como es inherente a A1. Igualmente, pueden darse condensaciones más complejas entre dos componentes que a su vez combinan condensaciones simples, como puede ser una vivencia de dolor psíquico (O2) y un estado orgánico de desvitalización (LI). Por ejemplo, los "ta, ta, ta” o “ipa! de Liliana condensaban LI y A1, mientras que "na na na” reunía LI y O2. Las holofrases se contraponen a la nominación del otro y de sí, a la que finalmente llegó Liliana. También es interesante tomar en cuenta el nombre inicialmente mencionado por la paciente, indescifrable, y que al terapeuta lo lleva a inferir una escena en que la paciente estaba acompañada por una empleada. La función de esta nominación es compatible con el mantenimiento de las holofrases, ya que la posición del personaje mentado era la de ayudante, quizá en una escena inherente al ejercicio del poder (A1) y el equilibrio de tensiones somáticas (LI).

En cambio, las situaciones prototípicas en las que prevalecen la nominación del otro y la del yo son otras tres: 1) nena, María (hablante), etc. + holofrase, 2) nena, María (hablante) + amiga nena o Silvia (amiga de la hablante), 3) yo-tú.

La primera situación corresponde a una primera salida de las holofrases, cuando estas se combinan con palabras con un sentido definido. El ejemplo del niño del juego del carretel (Freud, $1920 \mathrm{~g}$ ), quien pasó de decir "o-o-o" (holofrase) a decir "bebé o-o-o" resulta claro. Se advierte en este ejemplo que con la frase más compleja el niño pretendía relatar a su madre una escena ocurrida poco antes en que él jugaba a hacerse aparecer y desaparecer ante el espejo. A diferencia de la holofrase "o-o-o", que constituye una acción (A1), la frase "bebé o-o-o" es una relato ante un interlocutor. Una alternativa más compleja se da cuando bebé (o Pedrito) se combina con un amiguito, Mario, etc. En esta otra situación ya las holofrases no forman parte de la escena discursiva. El segundo tipo de autodenominación, que involucra al yo y al otro, es la que nos parece más afín con lo que ocurrió con la paciente. Un proceso más complejo y elaborado es el que permite la intelección del yo y el tú, así como de otros shifters. En tal caso no nos encontramos solo ante representaciones e identificaciones, sino ante procesos de pensamiento más elaborados que permiten advertir que las representaciones-palabras no necesariamente remiten a representaciones-cosa. Recordemos que Freud (1915e) sostiene que los contenidos inconscientes son de dos tipos: las representaciones y los procesos de pensamiento. Mientras que la representación-cosa deriva del vivenciar, los procesos de 
pensamiento son actos puramente internos, que no tuvieron un origen en el vivenciar, sino que, en ciertas circunstancias, pueden llegar a unirse a él (como cuando la palabra "yo" pasa a designar a un sujeto que habla). Pero no es este el tipo de auto-denominación por el que pugnaba Liliana.

En el primer tipo de auto-denominación ("bebé o-o-o") advertimos el surgimiento del lenguaje propio de A2, para el cual la palabra se enlaza con la cosa, y por lo tanto permite organizar un mundo "objetal" menos caótico. Las otras dos formas de autodenominación son inherentes al lenguaje FG, aunque en dos versiones distintas. En la primera prevalecen la identificación yo-objeto y en la segunda prevalecen los procesos de pensamiento y la capacidad para inteligir y usar los shifters. Quizá este último tipo de autodenominación quedara más interferido en la paciente por sus dificultades generales con la proferencia de palabras, ya que "yo" y "tú" son básicamente palabras, mientras que "Liliana" y "Adriana" constituyen nombres que remiten a representaciones, a entes supuestamente objetivos.

Algo parcialmente diferente ocurre con "toalla". El análisis del significado erógeno de la palabra pone en evidencia FG, y lo mismo ocurre con un sector de los actos de enunciación (la reiteración, la redundancia). También los componentes paraverbales corresponden a FG. Sin embargo la reiteración antes mencionada puede tener también un valor catártico, inherente a LI y la desestimación exitosa del afecto. Lo nuclear de "toalla" como acto de anunciación corresponde a A2 (la referencia a una situación concreta, objetiva). Como alusión a un objeto concreto (en una escena), tal palabra hubiera debido estar precedida y seguida por otras ("La toalla se ensució y me obligaron a lavarla"). Todo relato implica una secuencia y, subyacentemente, un enlace causal. El enlace causal, como el shifter, deriva del énfasis en los procesos de pensamiento ("porque”, del mismo modo que "yo", es una palabra que no remite a representaciones sino a actividades de pensamiento). De modo que la imposibilidad de combinar palabras para describir una secuencia en una escena se halla en el mismo nivel de la dificultad para usar el "yo". El reemplazo de la autodenominación tipo "yo" por el decir su propio nombre tiene su equivalente en decir "toalla" en lugar de una frase que remite a una escena concreta. Como acto de enunciación que constituye una referencia a una realidad concreta, "toalla" es una escena A2 combinada con la defensa acorde a fines fracasada. No ocurre lo mismo con "Liliana”, porque en realidad es la palabra que faltó decir al comienzo de la hora, cuando el terapeuta le preguntó a la paciente por su nombre. Claro que el tipo de respuesta que da la paciente, al insertar la dupla de nombrarse Liliana. Adriana, transforma al conjunto en una escena FG.

\section{Afasia, neurosis postraumática y afecciones psicosomáticas}

En trabajos previos en que estudiamos otros casos de pacientes afásicos advertimos que predominaba un tipo de escena (que corresponde a A2), y que expresa deseos de controlar o dominar la realidad (exterior e interior) utilizando la racionalidad. Dicha escena tiene una versión disfórica por fallas en el hablar, etc. El hecho era simultáneamente una expresión del retorno de una escena traumática, es decir, una expresión de la repetición del trauma durante la sesión (esta otra escena corresponde a LI). Pero el paciente podía reaccionar compensatoriamente ante esta situación utilizando otro estilo expresivo, incluyendo la mímica, gestos, exageraciones, una tendencia a embellecer los hechos (esta otra escena corresponde a FG). Especialmente la mímica es otra forma de narrar los hechos por medio de una identificación con otro. Usualmente, la mímica se combina con catarsis (LI). Pero algunos de los pacientes de la muestra permanecían apáticos, silenciosos o retraídos, utilizando recursos evitativos, oposicionistas o banales. También esta escena corresponde a LI. Cuando las intervenciones del terapeuta lograban romper este sistema defensivo, el paciente cambiaba al mismo estilo descrito poco más arriba (mímica, etc.). Pero aparecía un paso intermedio entre 1) la evitación y el retraimiento y 2) la mímica: un momento de intensa angustia; y el terapeuta necesitaba encontrar una manera de encarar este momento.

Estas escenas estaban conectadas con diferentes defensas: el retraimiento estaba conectado con la desmentida, el oposicionismo, con la represión + rasgos catacterológicos, y la mímica y otras manifestaciones expresivas, con defensas acorde a fines. Pero la evitación, la apatía, la banalidad, la catarsis y la intensa ansiedad permitieron inferir otra defensa, la desestimación del afecto. Como 
los otros mecanismos defensivos, la desestimación del afecto tiene tres posibles estados: exitosa, fracasada, ambas. Cuando es exitosa, el paciente puede mantener su equilibrio energético, cuando falla es invadido por una intensa angustia automática, cuando es exitosa/fracasada, prevalece la apatía. Desde este punto de vista notamos que ciertos pacientes comenzaban la entrevista con una desestimación del afecto exitoso/fracasado (apatía) combinada con un estado exitoso (banalidad, catarsis) de la defensa y luego, como consecuencia de las intervenciones del analista, dicha defensa fracasaba (angustia automática), como en ciertos momentos de las neurosis postraumáticas.

También investigamos las intervenciones del terapeuta. Intentamos detectar cuándo el intercambio paciente-terapeuta era fluido, y por qué, y cuándo el terapeuta ocupaba inadvertidamente la posición de un personaje en una escena traumática del paciente (atrapamiento clínico). Detectamos que en algunos momentos las intervenciones del terapeuta tenían el valor de una exigencia excesiva de la realidad que el paciente no podía responder. En ese caso, el terapeuta quedaba incluido en un atrapamiento clínico.

Hemos agregado un estudio sistemático de los actos del habla de los pacientes, para analizar sus dinamismos y conflictos durante la sesión. Detectamos que la mayoría de las interferencias y limitaciones lingüísticas aparecieron:1) al principio de la hora, en el momento del primer contacto, 2) cuando el paciente cambiaba desde el estado exitoso/fracasado de la desestimación del afecto al estado fracasado de dicha defensa. El rasgo en común de ambas situaciones es el contacto, especialmente el contacto con los propios sentimientos (segundo momento del aumento de las limitaciones lingüísticas).

Concluimos que los pacientes afásicos pueden ser considerados como un subgrupo dentro de las neurosis postraumáticas. En este subgrupo la situación traumática (que usualmente corresponde al momento del accidente y el coma) retornaba por dos caminos: 1) algunas escenas cargadas de intensa ansiedad, 2) las perturbaciones lingüísticas, y el posterior momento de recuperación se presentaba en el uso de la mímica, las exageraciones, etc.

El caso de Liliana que acabamos de exponer y analizar permite testear nuestra propuesta previa. En la paciente se advierte sobre todo un abroquelamiento exitoso en un rasgo caracterológico que le permite neutralizar los riesgos del fracaso de la desestimación del afecto y la irrupción de la angustia automática. Claro que tal éxito de una defensa patógena resulta costoso, como se advierte por su inversa, el sentimiento de logro que tuvo Liliana cuando pudo proferir su nombre y el de su amiga. La paciente compensaba dichas limitaciones apelando a sus componentes paraverbales y gesticulares, pero al mismo tiempo con ello lograba apuntalar su abroquelamiento caracterológico. Sea como fuere, no es posible diagnosticar a la paciente como una neurosis traumática, ya que no aparecen las crisis de angustia y el retorno de los episodios insoportables. Es notable que el período más resistencial de la sesión (segundo momento) haya comenzado cuando la paciente negó haber sentido miedo en el momento del accidente vascular, y en su lugar se hizo más evidente su testarudez. De modo que esta testarudez preservaba, al menos transitoriamente, a la paciente de la irrupción de la angustia. Sin embargo, tenemos evidencias de que este sistema defensivo fracasó con anterioridad y condujo a alteraciones somáticas (hipotiroidismo, diabetes), de modo que es posible conjeturar que algo similar podría ocurrir nuevamente, al fracasar la desestimación del afecto.

Claro que es posible que en la paciente no apareciera tanto una neurosis traumática sino más bien, otra vez, una neurosis tóxica, una neurosis actual que culmina en una alteración somática. Tanner (1996, 2003), citando a Eisenson (1984) y Craig y Cummings (1995) distingue entre afasias fluentes, en las que predomina un estado tóxico, y afasias no fluentes, en las que prevalece una neurosis postraumática. El caso que estudiamos en este trabajo parece contener una mezcla entre afasia no fluente (en el nivel verbal) y afasia fluente (en los niveles paraverbal y gesticular), por lo cual cabe preguntarse por la validez del nexo entre los tipos de afasia, lo tóxico y lo traumático. Más bien podríamos decir que el predominio de los componentes paraverbales y gesticulares por sobre la verbalización transforma a la paciente en fluente. 
A su vez, la categorización de estos dos sustratos psíquicos alternativos para las afasias (es decir, una patológica tóxica o una traumática) puede ser refinada si hallamos puntos de articulación entre tales sustratos. El punto básico de articulación parece hallarse sobre todo en la referencia a la defensa, la desestimación del afecto y su estado: si la defensa es exitosa, prevalece una euforia tóxica, y si resulta exitosa/fracasada predomina el componente traumático, claro que neutralizado. Las diferencias parecen darse respecto del fracaso de la defensa, porque en algunas ocasiones predominan los síntomas de las neurosis traumáticas (la irrupción de la angustia y recuerdos insoportables) y en otras ocasiones los síntomas de las neurosis actuales (afecciones psicosomáticas).

\section{Conclusiones}

1. Es conveniente revisar el enfoque freudiano del aparato del lenguaje (que enlaza la representación-palabra con la representación-cosa), e incluir al menos otros dos tipos de representación-palabra: 1) las que se enlazan con la representación-yo o representación-cuerpo, y 2) las que se enlazan con el pensar inconciente.

2. Cabe preguntarse si la contraposición entre afasia fluente y no fluente constituye un camino pertinente para avanzar hacia el estudio de las diferencias en cuanto a las estructuras clínicas.

3. La oposición entre afasia con la estructura de una neurosis tóxica y la afasia con una organización afín a las neurosis traumáticas ofrece un enfoque útil para pensar las similitudes y diferencias clínicas entre las manifestaciones.

4. Ambas organizaciones (tóxicas y traumáticas) a su vez se unifican en torno de una misma defensa (desestimación del afecto), que resulta exitosa en las afasias con una neurosis tóxica y exitosa/fracasada en las afasias con una neurosis traumática.

5. Ambas organizaciones psíquicas ponen en evidencia una regresión al funcionamiento del yo-realidad inicial, el más elemental de todos, el cual, además, se halla perturbado. 


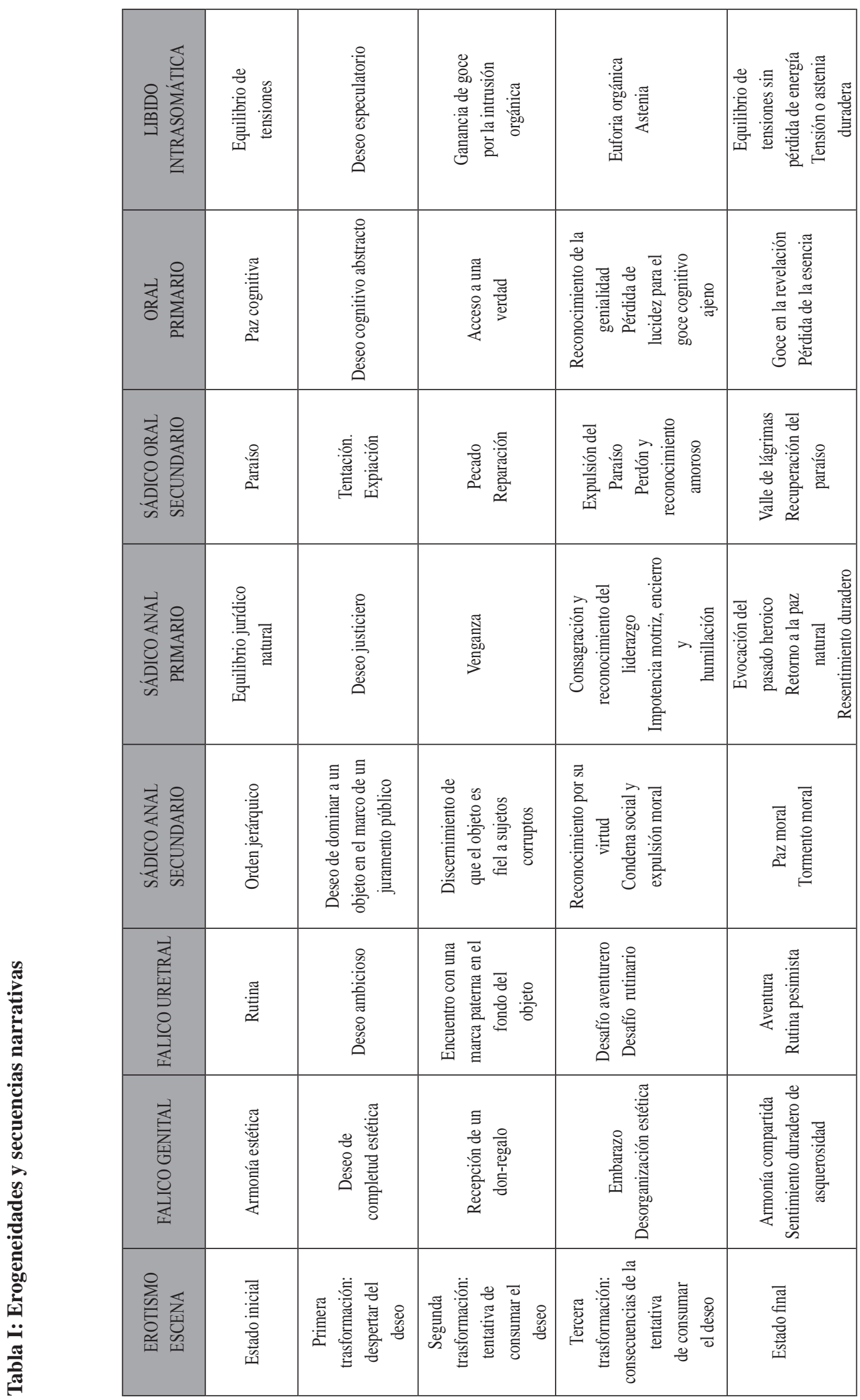




\section{Referencias}

Craig, A., Cummings, J. (1995). Neuropsychiatric aspects of aphasia. En Kirchner (Ed.). Handbook of neurological speech and language disorders. NY: Marcel Dicleker.

Eisenson, J. (1984). Adult aphasia (2 Ed.). Prentice Hall.

Freud, S. (1891b). La afasia. Buenos Aires, Nueva Visión, 1973.

(1905d). Tres ensayos de teoría sexual, en AE, vol. 7.

(1915e). “Lo inconciente”, en AE, vol. 14.

(1920g). Más allá del principio del placer, en AE, vol. 18.

(1924b). “Neurosis y psicosis”, en AE, vol. 19.

(1926d). Inhibición, síntoma y angustia, en AE, vol. 20.

(1950a \{1895\}) “Proyecto de psicología”, en Los orígenes del psicoanálisis, AE, vol. 1.

Hentschel, U., Draguns, J. G., Ehlers, W. \& Smith, G. (2004). Defense mechanisms: current approaches to research and measurement. En U. Hentschel (Ed.). Theoretical, research and clinical perspectives. Elsevier, Amsterdam: The Netherlands.

Kaplan-Solms, K., \& Solms, M. (2000). Clinical studies in neuro-psychoanalysis: Introduction to a depth neuropsychology ( $2^{\circ}$ Ed.). London \& New York: Karnac.

Maldavsky, D. (1986). Estructuras narcisistas. Constitución y transformaciones. Buenos Aires: Amorrortu Editores.

Maldavsky, D. (1995). Pesadillas en Vigilia, sobre neurosis tóxicas y traumáticas. Buenos Aires: Amorrortu Editores.

Maldavsky, D. (2003). La investigación psicoanalítica del lenguaje: algoritmo David Liberman. Buenos Aires: Editorial Lugar.

Maldavsky, D., Aguirre, A., Alvarez, L., Bodni, O., Britti, A.M., Buceta, C.,Bustamante, B., Cantis, J., Cusien, I., de Durán, R., Follmann, A., García Grigera, H., Garzoli, E., Goldberg, J., Iusim, M., Kazez, R., Legaspi, L., Manson, M., Miceli, G., Neves, N., Rembado, J.M., Rodríguez Calo, M., Roitman, C.R., Romano, E., Tarrab, E., Tate de Stanley, C., Widder, F. (2005). Systematic research on psychoanalytic concepts and clinical practice: the David Liberman algorithm (DLA). Buenos Aires: UCES editorial.

McDougall, J. (1991). Teatros del cuerpo. Madrid: Yebenes.

Panksepp, J. (1998). Affective neuroscience: The foundations of human and animal emotions. N.Y.: Oxford University Press.

Tanner, D. (1996). An introduction to the psychology of aphasia. Dubuque, IA: Kendall-Hunt.

Tanner, D. (2003). Eclectic perspectives on the psychology of aphasia. Journal of allied health, Winter, 3, 256-260. 


\section{Descripción de la revista y alcance de la línea editorial}

Summa Psicológica UST, Revista de Psicología de la Universidad Santo Tomás de Chile, es una publicación que acoge y difunde trabajos de carácter teórico y empírico enmarcados en, o conectados con, el campo de la ciencia psicológica. Entendemos aquí por 'campo psicológico' el extenso espacio de investigación y reflexión concerniente a la subjetividad y el comportamiento humano, cuya rica complejidad solicita, tal vez hoy más que nunca, la concurrencia e integración de múltiples marcos epistemológicos y formas discursivas distintas. Por ello, la revista quiere permanecer abierta tanto a trabajos de corte empírico-analítico (todas las líneas de investigación estándar dentro de la 'ciencia psicológica'), como a investigaciones y estudios de tipo teórico y conceptual (allí donde lo 'psicológico' se deja ver bajo la mirada de las humanidades y la reflexión filosófica). Todo lo que se exige, en términos tópicos, es que los escritos aborden temas insertos en el campo extenso de lo psicológico, o que tengan puntos relevantes de encuentro con él.

La periodicidad de la revista es semestral, y sus números aparecen en julio y diciembre de cada año.

La revista cuenta con una única sección: Artículos (sean de corte empírico o teórico conceptual).

Las opiniones expresadas en los artículos son de exclusiva responsabilidad de los autores y no comprometen a la Escuela de Psicología de la Universidad Santo Tomás, ni representan necesariamente el pensamiento de esta casa de estudios superiores.

\section{Normas de Publicación}

1. Los artículos enviados a Summa Psicológica UST deben ser inéditos, y no deben figurar simultáneamente en procesos de evaluación y selección para otras revistas.

2. Los autores recibirán vía e-mail el acuso de recibo de sus colaboraciones.

3. Sólo los artículos que cumplan con los requisitos de contenido y forma estipulados por Summa Psicológica UST (ver punto III. Instrucciones para los autores) serán enviados a evaluación.

3. Para su evaluación, los artículos son remitidos a pares académicos expertos (en el área temática del artículo, en aspectos metodológicos), asociados a Summa Psicológica UST en calidad de Consultores Externos. Todo ello bajo estricto anonimato del autor.

4. La decisión de aceptar o rechazar los artículos es tomada finalmente por el Comité Editor, teniendo como base las evaluaciones informadas por los expertos.

5. El proceso completo de evaluación y revisión de los artículos tiene un plazo máximo de 5 meses.

6. Tomada la decisión por parte del Comité Editor, ésta es comunicada vía e-mail al autor por el coordinador de la revista.

7. En caso de ser rechazado el artículo, el autor recibirá un resumen con las observaciones y sugerencias hechas por los evaluadores. El nombre de los evaluadores queda en estricta reserva y no es proporcionado al autor. El autor tendrá, a partir de la comunicación hecha por el coordinador, un plazo de 3 meses para hacer las correcciones pertinentes y volver a enviar el escrito. De no presentar el artículo dentro del plazo señalado, éste queda considerado como ‘nuevo artículo' y pasa a ser evaluado desde el inicio del proceso.

8. El autor cuyo artículo es aceptado para ser publicado, tiene derecho a un ejemplar de la revista y a 10 separatas. Este material se envía por correo a la dirección señalada por el autor, dentro de los meses de julio-agosto y diciembre-enero, según se trate del primer o segundo número del año. En caso de haber más de un autor, el material se envía al autor principal.

9. Para efectos de edición, el Comité Editor se reserva el derecho a efectuar las modificaciones y correcciones de prueba necesarias en los artículos para mantener el estilo formal de Summa Psicológica UST. 


\section{Instrucciones para los autores}

1. Los artículos deben ser enviados vía E-mail y en formato Word al coordinador de la revista (dirección: summapsicologicaust@santotomas.cl). El archivo debe venir identificado con el apellido del autor, seguido de la abreviación del sistema de normas que ha utilizado para redactar el artículo (APA o MLA). Si hay más de un autor, debe identificarse solo con el apellido del autor principal (Ejemplo: SalinasAPA, MoralesMLA).

2. El artículo debe comenzar con el título en castellano e inglés, seguido inmediatamente de un resumen en castellano e inglés (de 100 a 150 palabras), y al menos tres palabras claves (en castellano y en inglés) que señalen los conceptos centrales tratados en el texto. El artículo no debe venir con el nombre del autor.

3. En archivo aparte debe venir el título del artículo, seguido del nombre del autor (o autores), su dirección postal, dirección E-mail, teléfonos, e institución a la que se encuentra afiliado actualmente (sea en calidad de académico o alumno).

4. Los artículos deben tener una extensión máxima de 10.000 palabras o 30 páginas escritas en hoja tamaño carta, párrafos justificados, a doble espacio y en letra Times New Roman $n^{\circ} 12$. Esta extensión incluye tablas, figuras, notas y referencias.

5. Los artículos de investigación empírica deben ser redactados según las normas vigentes de la American Psychological Association, APA (ver ejemplos señalados más abajo). Su estructura debe contemplar: introducción, método, resultados, discusión y referencias. Los trabajos que no cumplan con estas exigencias formales serán devueltos para ser corregidos.

6. Los artículos de investigación teórica pueden ser redactados según normas APA, o según las normas vigentes MLA Modern Language Association (ver estilos sugeridos más abajo a modo de ejemplo). Los trabajos que no cumplan con estas exigencias formales serán devueltos para ser corregidos.

7. Las figuras, imágenes, gráficos y tablas, deben venir incorporados en el texto. Las imágenes, gráficos y demás elementos, aunque vengan en color, se publicarán solamente en blanco y negro.

8. Las notas deben venir numeradas consecutivamente y ubicadas a pie de página, escritas en letra Times New Roman $n^{\circ} 10$, párrafo justificado y espaciamiento doble.

Normas acerca de citas y referencias: algunos ejemplos ilustrativos.

I. Estilo según normas APA. Exigido estrictamente para artículos de investigación empírica.

1) Citas no textuales a modo de resumen o paráfrasis. Las formas pueden ser las siguientes:

Según Alvarez (1993), la violencia intrafamiliar supone siempre una relación fundada en la desigualdad de poder.

En 1988 Sternberg formuló una nueva aproximación al estudio de la inteligencia humana.

En los mecanismos de aprendizaje pueden distinguirse procesos tanto de asimilación como de acomodación (Piaget, 1980).

La idea general es que vayan señalados el autor y el año de la publicación que se está parafraseando o resumiendo.

2) Citas textuales. Si tienen menos de 40 palabras se utiliza la siguiente forma:

Los estudios exploratorios acerca del maltrato infantil "tienen utilidad solamente como aproximación fenomenológica a los determinantes subjetivos del victimario” (Hernández \& Salas, 1999, p. 20).

Si tienen más de 40 palabras, se omiten las comillas y se cita en texto aparte con un margen más amplio.

El vínculo materno filial se torna así un espacio amenazante y persecutorio por definición. En este tipo de relaciones objetales: 
El objeto aparece escindido e introyectado igualmente en tal condición, sin integración posible y con una carga paranoica, tan activa y poderosa, como lo es también la intensa necesidad sentida, todavía, de permanecer al cuidado y amparo de este mismo objeto. El vínculo con la madre se torna peligrosamente en un espacio relacional autoperpetuante. (Valladares, García \& Storadi, 1987, p. 79).

3) Citas de trabajos con más de un autor.

En caso de que existan dos autores, deben mencionarse los apellidos de ambos todas las veces que se cita la obra. Si se los menciona entre paréntesis, deben unirse con el signo \&. Si se los menciona en el cuerpo del texto, se los une con la letra "y". Ejemplos:

Los diseños cuasi-experimentales tendrían para este tipo de investigación una utilidad ciertamente limitada (Torres \& Araya, 1999).

Torres y Araya (1999), señalan que los diseños cuasi-experimentales tendrían para este tipo de investigación una utilidad ciertamente limitada.

Si se trata de entre 3 y 5 autores, se mencionan todos en la primera cita, y en las sucesivas sólo se menciona el apellido del primer autor (principal) seguido de la abreviación "et al.”. Si se trata de 6 o más autores, desde un inicio sólo se menciona el primer autor seguido de "et al.”. Ejemplo:

Vargas, Cameron y Marías (2000) omiten en su categorización psicopatológica la presencia de rasgos antisociales.

Al comparar estas aproximaciones, Vargas et al. (2000) señalan que el componente antisocial queda entonces relegado únicamente al campo penal.

4) Referencias. En la lista de referencias, enumerada siempre al final del artículo, deben señalarse todas y solamente las fuentes utilizadas puntualmente para elaborar el artículo (no se mencionan lecturas, manuales o trabajos a modo de sugerencia al lector, ni como profundización ni como ampliación del tema). Se enumeran por orden alfabético de autor. Si se ha consultado más de un trabajo perteneciente a un mismo autor, deben ordenarse por fecha comenzando por la publicación más antigua. Si el autor aparece como autor principal en obras colectivas, debe comenzarse por las obras en las que aparece como autor individual. Las referencias que comparten los mismos dos o tres primeros autores, deben ordenarse alfabéticamente considerando al tercer o cuarto autor respectivamente.

Referencia de publicaciones periódicas (revistas, boletines, diarios).

Autor o autores (año) Título del artículo. Nombre de la revista, Volumen (número), páginas. Ejemplo:

Berstein, F., Fisher, G., \& McGove, J. (2002) Childhood and speech acts. Journal of social behavior, 21 (3), 99-115.

Referencia de publicación no periódica (libros).

Autor o autores (año) Título de la obra. Ubicación: Editorial. Ejemplo:

Grondona, P. (1977) La adolescencia: travesía de la identidad. Barcelona, España: Alta Vista.

Referencia de partes (capítulos) de libros, readings o compilaciones.

Autor o autores (año) Título del capítulo. En autor o autores editores/compiladores (Ed., o Comp.), Título del libro (páginas del capítulo). Ubicación: Editor. Ejemplo:

Fay, C., \& Hanson, B. (2003) Stress resistance and mental health. En W. Frege \& C. G. Denevue (Eds.), Mental health: Contemporary issues (pp. 211-234). New York, N.Y., EE.UU.: North Lincoln University Press.

Más información acerca de cómo citar y referir otras fuentes (conferencias, comunicaciones personales, entrevistas, páginas electrónicas, etc.), consultar en 1) www.apa.org, 2) www. apastyle.org/elecsource.html, o 3) http://owl.english.purdue.edu/handouts/research/r apa.htlm. 
II. Estilo según MLA. Especialmente sugerido para artículos de carácter teórico-reflexivo, ligados a las formas discursivas de las humanidades y la filosofia.

1) Citas textuales de libros en papel. Las citas en el texto, si son breves, deben ir entrecomilladas. Si son citas extensas (4 líneas o más) deben ir en renglón aparte, sin comillas y con márgenes adentrados.

Los datos a señalar para cada cita son: apellido del autor, página de donde se extrajo la cita, y título abreviado de la obra escrito en itálica, en caso de que se trabaje con más de una obra perteneciente al mismo autor. Al final de cada cita, entre paréntesis debe señalarse la información que no ha sido mencionada en el cuerpo del texto o párrafo. Es decir, si la cita se inserta sin haber mencionado al autor, entonces entre paréntesis se señala el apellido del autor y la página, o apellido, título abreviado de la obra y página, en caso de que se trabaje con más de una obra perteneciente a un mismo autor.

Ejemplo de cita textual breve cuando se está trabajando con una sola obra del autor:

Las formas de pensamiento "tendrían una sintaxis previa y fundante respecto de las formas del lenguaje natural” (Fodor 122).

Ejemplo de citas textuales breves cuando se está trabajando con más de una obra perteneciente al mismo autor:

Las formas de pensamiento "tendrían una sintaxis previa y fundante respecto de las formas del lenguaje natural” (Fodor, Cognición y lenguaje 122). Sin embargo, lo propiamente fundante del pensamiento respecto del lenguaje sería su "estatus representacional simbólico, donador de todo el espesor semántico que portan los conceptos” (Fodor, Panorámica de los conceptos 98).

Si el autor es mencionado en el cuerpo del texto, entonces entre paréntesis sólo se señalan los datos que restan para identificar sin equívocos la fuente de la cita.

Ejemplo de esta cita cuando se trabaja con una sola obra del autor:

Según Habermas, "el psicoanálisis pone en práctica una conjunción novedosa de estrategias tanto explicativas como hermenéuticas” (122).

Ejemplo de esta cita cuando se trabaja más de una obra perteneciente al mismo autor:

Según Habermas, "el psicoanálisis pone en práctica una conjunción novedosa de estrategias tanto explicativas como hermenéuticas” (Teoría y praxis 122).

Ejemplo de cita extensa (4 líneas o más):

La habitual conciencia de sí, especialmente en aquellos actos que llamamos morales, suele sucumbir ante una serie de sesgos:

No son solamente los espectadores de un acto quienes miden con frecuencia la moralidad o inmoralidad por sus consecuencias; no, el autor mismo lo hace. Pues los motivos y las intenciones rara vez son lo suficientemente claros y sencillos, y a veces incluso la memoria parece turbada por las consecuencias, de modo que atribuimos a su propia acción motivos falsos o hacemos de motivos no esenciales los esenciales. (Nietzsche 85)

Estas normas se aplican de igual modo si se trata de un autor institucional o corporativo (ONU, UNESCO, etc.).

La idea general de esta forma es que se señale entre paréntesis sólo aquella información que no ha sido mencionada en el cuerpo del texto, y que el lector necesitaría en caso de requerir la fuente exacta.

2) Citas de fuentes en Internet. Se procede siguiendo los mismos criterios señalados para textos en papel, pero reemplazando la información de número de página por la expresión "en línea". Ejemplo:

La doctrina de las epistemes, y especialmente aquella que funda las formas discursivas de las ciencias humanas, sería probablemente una de las más débiles construcciones foucaultianas (Gutierrez, en línea). 